\title{
Çukurova bölgesi mısır tarlalarında çakal kavunu (Cucumis melo var. agrestis Naudin) ve tarla sarmaşı̆̆ı (Convolvulus arvensis L.)'nın mücadelesi
}

Control methods of field muskmelon (Cucumis melo var. agrestis Naudin) and field bindweed (Convolvulus arvensis L.) in the corn fields of Çukurova region

\author{
İlhan ÜREMiş ${ }^{1}$ (D), Halil Hikmet KURU2 \\ ${ }^{1}$ Hatay Mustafa Kemal Üniversitesi, Ziraat Fakültesi, Bitki Koruma Bölümü, Antakya-Hatay. \\ ${ }^{2}$ Syngenta Tarım San. ve Tic. A.Ş. Yüreğir-Adana.
}

MAKALE BILGISI / ARTICLE INFO

\section{Makale tarihçesi / Article history:}

DOI: $10.37908 /$ mkutbd.936209

Geliş tarihi /Received:11.05.2021

Kabul tarihi/Accepted:13.07.2021

\section{Keywords:}

Cucumis melo var. agrestis, Convolvulus arvensis, herbicides, hoeing, integrated weed management.

\footnotetext{
Corresponding author: ilhan ÜREMiş

$\bowtie$ : iuremis@yahoo.com
}

\section{ÖZET / A BSTRACT}

Atıf / Citation: Üremiş i, Kuru HH (2021) Çukurova bölgesi mısır tarlalarında çakal kavunu (Cucumis melo var. agrestis Naudin) ve tarla sarmaşığı (Convolvulus arvensis L.)'nın mücadelesi. MKU. Tar. Bil. Derg. 26(3) : 554-564. DOI: 10.37908/mkutbd.936209 


\section{Giriş}

Tarımın başlıca amacı, çevre bilinci korunarak, birim alandan olabildiğince fazla miktarda ve yüksek kalitede ürün elde etmektir. Bu amaca ulaşmak için öncelikle uygun yetiştirme koşulları sağlanarak, doğal dengeye zarar vermeden hastalık, zararlı ve yabancı otlar gibi bitki koruma sorunlarının çözülmesi gerekmektedir. Bitkisel üretimde çevre koşulları haricinde ürün kayıplarının ana sebeplerinden birisi de yabancı otlardır (Tepe, 2014; Güncan, 2019; Üremiş ve Uludağ, 2020). Dünya'da belli başı kültür bitkilerinde (mısır, buğday, çeltik, pamuk, soya) zarara neden olan hastalık, zararlı ve yabancı otların yol açtığı ürün kaybı yaklaşık \% 67.15 olup, bunun \% 21.75'i zararlılardan, \% 13.78'i hastalıklardan ve \% 31.62 'si ise yabancı otlardan kaynaklanmaktadır (Oerke ve Dehne, 2004).

Yabancı otların neden olduğu ürün kaybının kültür bitkisine, yabancı ot türüne ve yoğunluğuna bağlı olarak \% 20-100 arasında bir oranda değişebildiği, ayrıca yabancı otların birçoğunun kültür bitkilerinden daha fazla su ve bitki besin maddesine ihtiyaç duyduğu buna bağı olarak yabancı otların birçok kültür bitkisinden daha fazla rekabet yeteneğine sahip olduğu ifade edilmektedir (Lacey, 1985; Zimdahl, 2018; Üremiş ve ark., 2020). Besin maddesi ve suyun az olduğu alanlarda yabancı otlardan kaynaklanan zarar daha yüksek olabilmektedir. Kısıtlı azot koşullarında yabancı otlardan kaynaklanan zarar \% 45-50 oranında gerçekleşirken yeterli azot bulunması halinde bu zarar \% 15 civarında olabilmektedir (Rajcan ve Swanton, 2001). Amaranthus retroflexus yoğunluğunun $0.5-8$ bitki olarak değiştiği koşullarda, mısır bitkisinin verim kaybı \% 5-34 arasında değişebilmektedir (Knezevic ve ark., 1994; Knezevic ve ark., 1997). Mısır ve pamuk gibi bazı kültür bitkileri ilk gelişme döneminde, yabancı otlara karşı rekabet gücü zayıftır, burada gerekli mücadele yapılmadığı takdirde kültür bitkisi + yabancı otlu gün sayısına bağlı olarak ürün kaybı \% 80'lere kadar çıkabilmekte olup bu nedenle de yabancı ot mücadelesinin önemi ortaya çıkmaktadır (Uludağ ve ark, 2006; Zimdahl, 2018). Mısır bitkisi ekiminden itibaren ilk 4-6 haftalık dönemde, özellikle başlangıçta yabancı otlara karşı çok duyarlıdır. Çıkıştan itibaren $2-8$ yapraklı dönemde, yabancı otlar gelişmelerinin \% 20'sini mısır ise \% $5^{\prime}$ ini tamamlamaktadır. Bu dönem yabancı ot rekabetinin en fazla olduğu dönem olup, bu devrede yabancı otların mısırda \% 18-65 arasında bir oranda ürün kaybına neden olabilmektedir (Özer ve ark., 1998; Fuksa ve ark., 2002; Doğan ve ark., 2004; Işık ve ark., 2006; Uludağ ve ark., 2012; Üremiş ve ark., 2009).
Son yıllarda özellikle mısır alanları gerek çakal kavunu (Cucumis melo var. agrestis Naudin, CUCME) ve gerekse tarla sarmaşı̆̆ı (Convolvulus arvensis L., CONAR) tarafından tehdit edilmektedir. Bunlardan; çakal kavunu; tek yıllık, 1.5 m'ye kadar büyüyebilen, tırmanıcı, sarılıcı ve/veya yatık gelişen, yalnızca tohumlarıyla çoğalan otsu ve istilacı bir bitkidir. Dünyanın ılıman ve tropikal kısımlarının doğal bitkisidir. Bitkinin Çukurova bölgesine nasıl bulaştığı tam olarak bilinmemekle birlikte zaman zaman süs bitkisi olarak yetiştirildiği alanlardan veya benzer alanlardan boş alanlara, demiryollarına ve piknik alanlarına oradan da kültür bitkisi yetiştirilen alanlara bulaşmasından kaynaklandığı tahmin edilmekte olup, bitkinin tarım alanlarında ilk görülmesinden itibaren çok kısa sürede başta soya, pamuk, yerfıstığı ve mısır olmak üzere Çukurova bölgesinin neredeyse tamamına bulaştığı görülmektedir (Hançerli, 2017; Xu ve ark., 2017; Uludağ ve ark., 2021). Diğer bitki tarla sarmaşığı ise; çok yıllık, çiçekli, geniş yapraklı hem tohumları hem de kökleriyle çoğalan, sarılıcı ve kozmopolit bir yabancı ottur. Dünyanın hemen hemen her tarafına dağıımış durumda olup mevcut sorun her geçen gün daha da artmaktadır. Ülkemizdeki durumu bundan farklı değildir. 1940'larda ülkenin yaklaşık 2/3'ünde bulunurken günümüzde ülkenin neredeyse tamamında olmak üzere, başta pamuk, sebze, yerfıstığı, meyve bahçeleri, buğday ve mısır olmak üzere tüm yazlık ürünlerde görülmektedir. Bu yayılımda bitkinin üstün adaptasyon kabiliyeti ve mevcut kontrol uygulamalarından çok iyi sonuç alınamaması gelmektedir. Mücadelede özellikle meyve bahçelerinde ve boş alanlarda total herbisitlerden iyi sonuç alınabilirken kültür alanlarında yeterli sonuçlar alınamadığından bu konuda beklentiler devam etmektedir (Kuntay, 1944; Uygur ve ark., 1986; Americanos, 1994; CABI, 2018).

Yabancı otlarla mücadele yöntemlerinden biri olan biyolojik savaş yöntemi gerek uygulama alanlarının yaygın olmaması, gerekse de geniş alanlarda ekonomik olmamaları nedeniyle üretici tarafından fazla tercih edilmemektedir (Kadıoğlu ve ark., 1998; Uludağ ve ark., 2018). 1940'lardan sonra çok sayıda etkili herbisitin keşfiyle birlikte, geniş tarım alanlarında etkin bir yabancı ot mücadelesi yapılabilir duruma gelmiştir. Bu nedenle yabancı otlarla mücadele genellikle mekanik yollarla birlikte herbisit uygulamaları şeklinde yapılmaktadır. Kimyasal mücadelenin alternatifinin çok fazla olmaması, uygulanabilirliğinin kolay olması, kısa sürede etki göstermesi, ekolojik koşullardan çok fazla etkilenmemesi ve diğer yöntemlere göre maliyetinin az olması nedeniyle en çok tercih edilen yöntemdir (Üremiş ve ark., 1996; Kudsk ve Streibig, 2003; Kaya ve Üremiş, 2020). Ancak, mısırda yabancı otların 2-4 yapraklı gibi erken büyüme 
dönemindeki hassasiyetlerinin daha yüksek olduğu ve herbisit dozlarının \% 30-40 oranında azaltıldığı uygulanmalarda bile \% 90 oranında kontrol sağladığı bildirilmektedir (Doğan ve ark., 2005). Diğer taraftan, yeni tarım tekniklerinin hızlı değişimiyle birlikte insan gücünün pahalılaşması, herbisit kullanımının artmasına neden olmuş, bu uygulama beraberinde birçok yeni çevre problemi getirmiştir. Aşırı herbisit kullanımının toprakta, suda ve yiyeceklerde kalıntı sorunu yaratmasıyla insan sağlığını tehdit edecek boyutlara ulaşması, hedef dışı canlı organizmalara etki etmesi, çevre kirliliği yaratması ve florada değişikliklere yol açması sonucu bunların kullanımına kısıtlama getirilmek istenmektedir (Thonke, 1991). Bu nedenle kimyasal mücadele üretici tarafından en çok tercih edilen yöntem olmasına rağmen, en riskli yöntem olup bu nedenle uygulanmasında çok dikkatli olunması gerekmektedir (Mengüç, 2018).

Türkiye'de önemli bir tarım bölgesi olan Çukurova'da coğrafi ve iklimsel koşulları nedeniyle birçok tarımsal ürün yetişebilmektedir. Çukurova Bölgesi buğday ekim alanlarında farklı yabancı ot türünün herbisitlere karşı direnç kazanmasıyla bu yabancı otlara karşı etkili bir kimyasal mücadele uygulanamaması sebebiyle bölgede buğday verim ve kalitesi çok düşmüş olup, çiftçiler alternatif ürün olarak özellikle mısıra yönelmişlerdir. Ülkemizde ekonomik anlamda önemli bir yere sahip olan mısır (Zea mays L.) kullanım alanlarının artışıyla önemi günden güne artan bir kültür bitkisidir. Mısır insan gıdası ve hayvan yemi olarak değerlendirilmesinin yanı sıra endüstride; nişasta, şurup, şeker, bira ve alkol yapımında da kullanılmaktadır (Süzer, 2003).

Dünya tahıl üretimi ve alanı içerisinde mısır üretimi birinci sırada yer almaktadır. Ülkemiz toplam ekim alanı ve üretimi bakımından ise buğday ve arpadan sonra gelmektedir. Mısır ekim alanı yıllara göre değişmekle birlikte ortalama 650.000 ha, yıllık üretim ise yaklaşık 2.2 milyon ton kadardır. Bu üretimin \% 30'unu oluşturan Çukurova, mısır üretim politikasını belirleyen önemli yörelerden biridir (TÜiK, 2018). Mevcut iklim koşullarında, uygun çeşit ve girdiler kullanarak ülkemizin neredeyse tamamında mısır üretimi yapılabilmektedir. İkinci ürün yetiştiriciliğinin yaygınlaşması ile mısır üretim miktarı oldukça yüksek miktarlara ulaşmıştır, buna rağmen mısır üretimi yurtiçi talebi karşılayamamakta ve önemli miktarda ithalat yapılmaktadır. Son yıllarda bu rakam neredeyse 1 milyon tona ulaşmıştır. Özellikle yüksek verimli melez mısır çeşitlerinin yaygınlaşması, uygun girdi destekli modern yetiştirme tekniklerinin uygulanması ile mısır üretim miktarı artmakta olup 557 $\mathrm{kg} \mathrm{da-1}$ olan dünya ortalamasının üzerinde gerçekleşmektedir. Yüksek verim, üretici deneyimi, uygun fiyat, pazar şansının yüksek olması gibi nedenlere bağı olarak üretim alanları artmaktadır, ancak son yıllarda bazı bölgelerdeki su sorunu mısır üretimini zorlamaktadır (Han, 2016).

Günümüz mısır ekim alanlarında çıkış sonrası yabancı ot mücadelesi için kullanılan herbisitlerin çoğu nicosulfuron, rimsulfuron ve foramsulfuron gibi sülfonilüre grubuna dâhil herbisitlerdir. Her ne kadar 2,4$D$ amin etkili maddeli herbisitler de ruhsatlı olsalar da bu preparatlar bazı yabancı otlara karşı yeterli etkiyi gösterememekte ve aynı zamanda da uygun olmayan koşullarda (rüzgarlı havalar vb.) uygulandığında sürüklenerek çevredeki geniş yapraklı kültür bitkilerine de (özellikle pamuk) zarar verebilmektedir (Doğan ve Benlioğlu, 2007).

Üretici için çok önemli olan bu ürünün söz konusu yabancı otlardan korunması ve yeni mücadele yöntemlerine ihtiyaç olduğu bir gerçek olarak karşımıza çıkmaktadır. Bu nedenle çakal kavunu (CUCME) ve tarla sarmaşığının (CONAR) mücadele yöntemlerinin belirlenmesi çalışmanın amaçlarını oluşturmaktadır.

\section{MATERYAL ve YÖNTEM}

\section{Çalışma alanları ve özellikleri}

Mısır tarlalarındaki yabancı otlarla mücadele çalışmaları Haziran - Kasım 2017 döneminde Adana'nın İmamoğlu ilçesine bağlı Ayvalı (37 $18^{\prime} 48.1^{\prime \prime} \mathrm{N}, 35^{\circ} 43^{\prime} 41.2^{\prime \prime} \mathrm{E}$, birinci deneme) ve Menteş köylerinde $\left(37^{\circ} 15^{\prime} 01.3^{\prime \prime} \mathrm{N}\right.$, $35^{\circ} 42^{\prime} 51.2^{\prime \prime E}$, ikinci deneme) yürütülmüştür. İmamoğlu'na bağlı Ayvalı köyünde bulunan deneme alanı; hafif killi yapıda olup, hafif alkali karakter göstermektedir. Organik madde içeriği bakımından zayıf olan tarla az tuzlu ve hafif kireçli yapıdadır. Menteş köyünde bulunan deneme alanı ise; killi yapıda olup, hafif alkali karakter göstermektedir. Organik madde içeriği bakımından zayıf olan arazi orta tuzlu ve orta kireçli yapıdadır. İmamoğlu ilçesine ait iklim verileri Çizelge 1'de verilmiştir. Doğu Akdeniz bölgesi'nde bulunan çalışmanın yapıldığı alanlar genel olarak tipik Akdeniz iklimine sahip olup çalışma süresince elde edilen aylık ortalama değerlerin uzun yıllar ortalamasına yakın seyrettiği anlaşılmaktadır. 
Çizelge 1. İmamoğlu (Adana)'na ait meteorolojik veriler (Anonim, 2017)

Table 1. Meteorological data of Imamoğlu (Adana) (Anonim, 2017)

\begin{tabular}{lccccc}
\hline Aylar & $\begin{array}{c}\text { Max. Ort. Sıcaklık } \\
\left({ }^{\circ} \mathbf{C}\right)\end{array}$ & $\begin{array}{c}\text { Min. Ort. Sıcaklık } \\
\left({ }^{\circ} \mathbf{C}\right)\end{array}$ & $\begin{array}{c}\text { Ort. Sıcaklık } \\
\left({ }^{\circ} \mathbf{C}\right)\end{array}$ & $\begin{array}{c}\text { Ort. Nem } \\
(\%)\end{array}$ & $\begin{array}{c}\text { Toplam Yağış } \\
(\mathbf{m m})\end{array}$ \\
\hline Mayıs & 28.1 & 15.3 & 21.4 & 59.1 & 46.7 \\
Haziran & 34.9 & 20.1 & 26.7 & 56.5 & 23. \\
Temmuz & 40.3 & 22.3 & 30.6 & 49.8 & 13.3 \\
Ağustos & 37.9 & 24.7 & 29.9 & 61.3 & 8.3 \\
Eylül & 36.3 & 21.9 & 27.8 & 57.3 & 22.7 \\
Ekim & 28.6 & 13.8 & 21.1 & 42.8 & 56.4 \\
Kasım & 21.4 & 10.1 & 12.6 & 51.9 & 90.8 \\
\hline Yıllık Ortalama & $\mathbf{2 6 . 7}$ & $\mathbf{1 3 . 2}$ & $\mathbf{1 9 . 4}$ & $\mathbf{5 4 . 8}$ & $\mathbf{7 2 7 . 4}$ \\
\hline
\end{tabular}

\section{Deneme deseni ve araştırma konuları}

Çakal kavunu ve tarla sarmaşığının mücadelesine yönelik çalışmalar Tesadüf Blokları Deneme Deseni'ne göre 9 karakterli ve 3 tekerrürlü olarak kurulmuş çalışmada $3 \mathrm{~kg}$ $\mathrm{da}^{-1}$ ekim normunda, $25 \times 70 \mathrm{~cm}$ aralıkla ekilen DKC6590 (Dekalb) çeşidi tohumluk kullanılmıştır. Araştırmada her bir uygulama için $24 \mathrm{~m}^{2}(3 \times 8)^{\prime}$ den oluşan ve aralarında 1'er $\mathrm{m}$ mesafe (güvenlik şeridi) bulunan parseller oluşturulmuştur. Her parselde 4 mısır sırası yer almaktadır. Mısır yetiştiriciliği sırasında yapılan işlemlere ait bazı bilgiler Çizelge 2'de görülmektedir.

Çizelge 2. Mısır yetiştiriciliğinde yapılan işlemler ve dönemi

Table 2. Agronomic processes and period in corn cultivation

\begin{tabular}{|c|c|c|}
\hline Yapilan Uygulamalar & Ayvalı & Menteş \\
\hline Goble diskle sürüm (4 defa farklı yönde) & 08.06 .2017 & 20.06.2017 \\
\hline Taban gübreleme $\left(20-20-0,30 \mathrm{~kg} \mathrm{da}^{-1}\right)$ & 15.06 .2017 & 27.06.2017 \\
\hline Ekim makinası ile ekim (DKC6590 çeşidi) & 15.06.2017 & 27.06.2017 \\
\hline 1. sulama & 16.06.2017 & 28.06.2017 \\
\hline 2. sulama & 27.06.2017 & 10.07.2017 \\
\hline $\begin{array}{l}\text { Insektisit uygulama } \\
\left.\text { Lambda-cyhalothrin }\left(50 \mathrm{~g} \mathrm{l}^{-1}\right), 30 \mathrm{ml} \mathrm{da}^{-1}\right)\end{array}$ & 16.07.2017 & 23.07.2017 \\
\hline 3. sulama & 17.07.2017 & 25.07.2017 \\
\hline 4. sulama & 03.08 .2017 & 09.08.2017 \\
\hline $\begin{array}{l}\text { Insektisit uygulama } \\
\left.\text { Chlorantraniliprole }\left(100 \mathrm{gl}^{-1}\right)+\text { Lambda-cyhalothrin }\left(50 \mathrm{gl}^{-1}\right), 25 \mathrm{ml} \mathrm{da}^{-1}\right) \\
\text { Fungusit uygulama }\end{array}$ & 14.08.2017 & 20.08.2017 \\
\hline $\begin{array}{l}\text { Propiconazole }\left(125 \mathrm{~g} \mathrm{l}^{-1}\right)+\text { Azoxystrobin }\left(100 \mathrm{~g} \mathrm{l}^{-1}\right)+\text { Cyproconazole } \\
\left.\left(30 \mathrm{~g} \mathrm{l}^{-1}\right), 100 \mathrm{ml} \mathrm{da}^{-1}\right)\end{array}$ & 14.08.2017 & 20.08.2017 \\
\hline 5. sulama & 21.08.2017 & 25.08.2017 \\
\hline 6. sulama & 12.09.2017 & 15.09.2017 \\
\hline Hasat & 18.10 .2017 & 23.10 .2017 \\
\hline
\end{tabular}

Denemede çıkış öncesi, Isoxaflutole $\left(225 \mathrm{~g} \mathrm{l}^{-1}\right)+$ Thiencarbazone-Methyl $\left(90 \mathrm{~g} \mathrm{l}^{-1}\right)+$ Cyprosulfamide (150 $\mathrm{g} \mathrm{l}^{-1}$ ) (ISTC, $\left.30 \mathrm{ml} \mathrm{da}^{-1}\right)$; S-Metolachlor $\left(312.5 \mathrm{~g} \mathrm{l}^{-1}\right)+$ Terbuthylazine (187.5 $\mathrm{g} \mathrm{l}^{-1}$ ) (SMTE, $500 \mathrm{ml} \mathrm{da}{ }^{-1}$ ); Dimethenamid-P $\left(280 \mathrm{~g} \mathrm{l}^{-1}\right)+$ Terbuthylazine $\left(250 \mathrm{~g} \mathrm{l}^{-1}\right)$ (DPTE, $300 \mathrm{ml} / \mathrm{da})$; çıkış sonrası, Dicamba (\% 50) + Tritosulfuron (\% 25) (DITR, $25 \mathrm{ml} \mathrm{da}^{-1}$; Mesotrione (75 $\mathrm{g} / \mathrm{l})$ + Nicosulfuron $\left(30 \mathrm{~g} \mathrm{l}^{-1}\right)$ (MENI, $\left.200 \mathrm{ml} \mathrm{da}^{-1}\right)$; Foramsulfuron $\% 30$ + lodosulfuron- methyl-sodium \% 1 + Isoxadifen-ethyl \% 30 (FORA, $15 \mathrm{ml} \mathrm{da}^{-1}$ ) ve Nicosulfuron (40 $\mathrm{g} \mathrm{l}^{-1}$ ) (NICO, $125 \mathrm{ml} \mathrm{da}^{-1}$ ) etkili maddesine sahip herbisitler ve Çapa uygulamaları yapılmıştır. Uygulamalara ait bilgiler Çizelge $3^{\prime}$ de verilmiştir. 
Çizelge 3. Çalışmada ele alınan uygulamalar ve bazı özellikleri

Table 3. Applications in the study and some of their features

\begin{tabular}{|c|c|c|c|}
\hline Etkili Madde & Ticari İsmi & $\operatorname{Doz}\left(\mathrm{ml} \mathrm{da}^{-1}\right)$ & Uygulama Kodu \\
\hline \multicolumn{4}{|l|}{ Çıkış Öncesi Uygulama } \\
\hline $\begin{array}{l}\text { Isoxaflutole }\left(225 \mathrm{gl}^{-1}\right)+\text { Thiencarbazone-Methyl }\left(90 \mathrm{gl}^{-1}\right)+ \\
\text { Cyprosulfamide }\left(150 \mathrm{~g} \mathrm{l}^{-1}\right)\end{array}$ & Adengo SC 465 & 30 & ISTC \\
\hline S-Metolachlor $\left(312.5 \mathrm{~g} \mathrm{l}^{-1}\right)+$ Terbuthylazine $\left(187.5 \mathrm{~g} \mathrm{l}^{-1}\right)$ & Primextra Opti 500 SC & 500 & SMTE \\
\hline Dimethenamid-P $\left(280 \mathrm{~g} \mathrm{l}^{-1}\right)+$ Terbuthylazine $\left(250 \mathrm{~g} \mathrm{l}^{-1}\right)$ & Akris & 300 & DPTE \\
\hline \multicolumn{4}{|l|}{ Çıkış Sonrası Uygulama } \\
\hline Dicamba $(\% 50)+$ Tritosulfuron $(\% 25)$ & Arrat & 25 & DITR \\
\hline Mesotrione $\left(75 \mathrm{gl}^{-1}\right)+$ Nicosulfuron $\left(30 \mathrm{~g} \mathrm{l}^{-1}\right)$ & Elumis & 200 & MENI \\
\hline $\begin{array}{l}\text { Foramsulfuron } \% 30+\text { lodosulfuron- methyl-sodium } \% 1+ \\
\text { Isoxadifen-ethyl \% } 30\end{array}$ & Ekipp Super & 15 & FORA \\
\hline Nicosulfuron $\left(40 \mathrm{~g}^{-1}\right)$ & Sanson & 125 & NICO \\
\hline Çapa & - & - & ÇAPA \\
\hline Kontrol & - & - & KONT \\
\hline
\end{tabular}

Çalışmada kullanılan herbisitler, $3 \mathrm{~m}$ iş genişliğine sahip üzerinde 6 adet yelpaze meme bulunan (TeeJet, DG11002) $\mathrm{CO}_{2}$ basınçlı sırt pülverizatörü ile 3 atmosfer basınçta ve dekara $30 \mathrm{~L}$ ilaç normunda yapılmıştır. Yabancı ot ilaçlamaları Ayvalı köyü için; çıkış öncesi olarak 16.06.2017 tarihinde, çıkıs sonrası ise 05.07.2017 tarihinde, Menteş köyü için; çıkış öncesi olarak 28.06.2017 tarihinde çıkış sonrası ise 15.07.2017 tarihinde uygulanmıştır (Şekil 1a ve b).
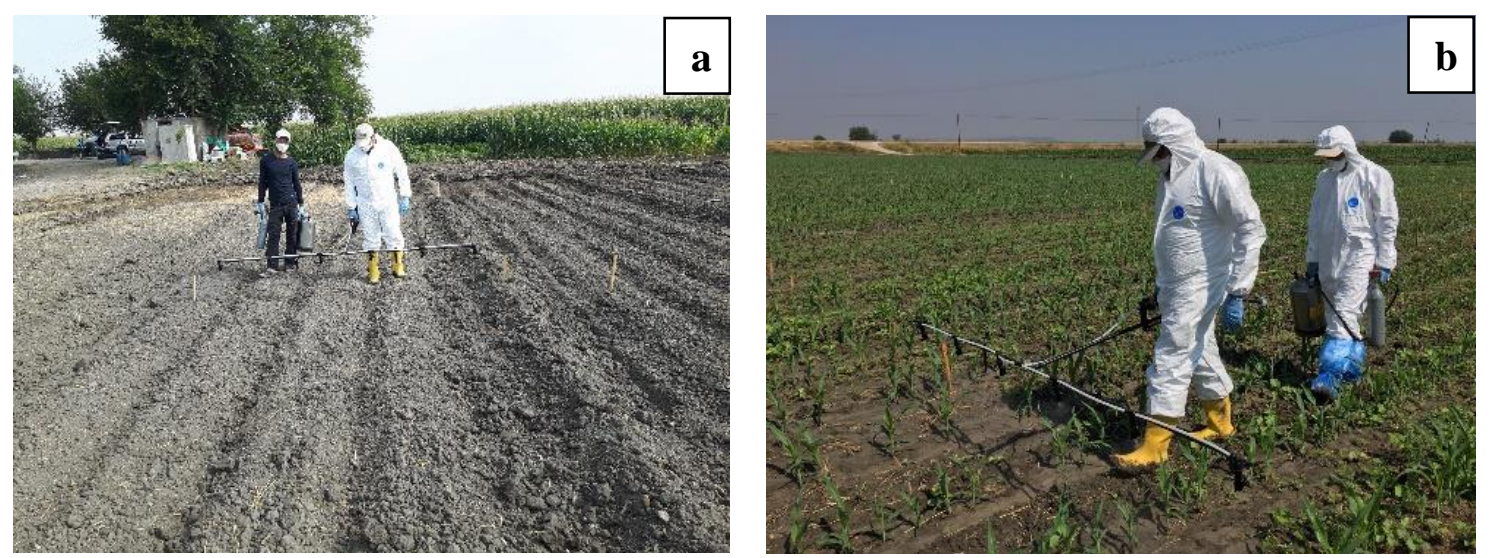

Şekil 1. Deneme alanında herbisitlerin uygulanması (a) çıkış öncesi uygulama ve b) çıkış sonrası uygulama).

Figure 1. Application of herbicides in the experimental area (a) pre-emergence and b) post-emergence).

Mekanik mücadele için yapılan el çapalarının ilki çıkış sonrası ilaçlamalarla birlikte, ikincisi ise bundan 15 gün sonra yapılmıştır. Uygulamalardan 28 gün sonra yabancı ot türlerine ait bitkilerin sayımı her bir parselde seçilen iki farklı $1 \mathrm{~m}^{2}$ lik çakılı alanlarda yapılmıştır. Uygulama yapılan parsellerden elde edilen veriler kontrol parselleri ile karşılaştırılarak etki değerleri tespit edilmiştir.

\section{istatistiki analizler}

Yabancı otlarla mücadelede elde edilen sonuçlara SPSS istatistik programında (ANOVA) istatistiki analiz uygulanmış ve ortalamaların karşılaştırılması \% 5 önem düzeyinde Duncan Çoklu Karşılaştırma testi ile yapılmış ve gruplandırılmıştır. Ayrıca, çalışmada elde edilen değerlerin standart hataları hesaplanmıştır. 


\section{BULGULAR ve TARTIŞMA}

Çakal kavunu (CUCME) ve Tarla sarmaşığı (CONAR)'na karşı mücadele yöntemlerinin etkinlikleri

Mısır tarlalarında bulunan çakal kavunu (CUCME) ve tarla sarmaşığına (CONAR) karşı herbisit uygulamaları ve mekanik mücadelenin etkinliklerini belirleme çalışmaları Adana'nın İmamoğlu ilçesine bağı Ayvalı ve Menteş köylerinde 2017 yılında yapılmıştır. Uygulamalara ait sonuçlar Çizelge 4'de verilmektedir.

Çizelge 4. Çukurova'da çakal kavunu ve tarla sarmaşığına karşı kullanılan mücadele yöntemlerinin etkileri (adet $\mathrm{m}^{-2}$ ) Table 4. Effects of control methods used against field muskmelon and field bindweed in Çukurova region (number $\mathrm{m}^{-2}$ )

\begin{tabular}{|c|c|c|c|c|c|}
\hline \multirow{2}{*}{$\begin{array}{c}\text { Uygulama } \\
\text { Dönemi }\end{array}$} & \multirow{2}{*}{ Etkili Madde } & \multicolumn{2}{|c|}{ CUCME } & \multicolumn{2}{|c|}{ CONAR } \\
\hline & & Ayvalı & Menteş & Ayvalı & Menteş \\
\hline \multirow{3}{*}{ 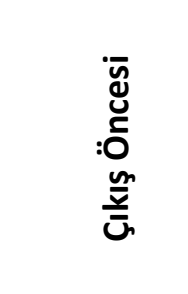 } & SMTE & $1.25 \pm 0.25 C^{*}$ & $1.50 \pm 0.29 C D$ & $2.25 \pm 0.48 C D$ & $3.50 \pm 0.28 \mathrm{CD}$ \\
\hline & ISTC & $1.25 \pm 0.25 C$ & $1.50 \pm 0.28 \mathrm{CD}$ & $1.75 \pm 0.25 \mathrm{D}$ & $2.75 \pm 0.25 C D$ \\
\hline & DPTR & $3.50 \pm 0.29 B$ & $3.75 \pm 0.48 B$ & $2.75 \pm 0.47 B C D$ & $4.00 \pm 0.41 B C$ \\
\hline \multirow{6}{*}{ 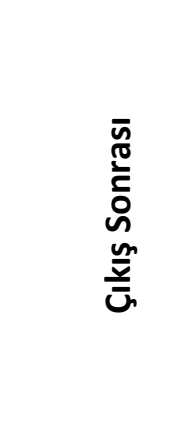 } & DITR & $3.75 \pm 0.48 \mathrm{~B}$ & $2.50 \pm 0.29 \mathrm{C}$ & $3.50 \pm 0.29 B C$ & $5.25 \pm 0.47 \mathrm{~B}$ \\
\hline & MENI & $1.25 \pm 0.25 C$ & $1.00 \pm 0.00 \mathrm{D}$ & $2.25 \pm 0.25 C D$ & $2.75 \pm 0.25 C D$ \\
\hline & FORA & $4.75 \pm 0.47 \mathrm{~B}$ & $3.75 \pm 0.25 B$ & $3.75 \pm 0.48 \mathrm{~B}$ & $5.25 \pm 0.48 \mathrm{~B}$ \\
\hline & NICO & $4.00 \pm 0.40 \mathrm{~B}$ & $3.75 \pm 0.25 B$ & $3.50 \pm 0.28 \mathrm{BC}$ & $5.25 \pm 0.47 \mathrm{~B}$ \\
\hline & ÇAPA & $3.75 \pm 0.75 B$ & $1.00 \pm 0.00 \mathrm{D}$ & $2.00 \pm 0.00 \mathrm{D}$ & $2.25 \pm 0.25 \mathrm{D}$ \\
\hline & KONT & $14.50 \pm 1.32 \mathrm{~A}$ & $8.25 \pm 0.85 A$ & $5.50 \pm 0.65 \mathrm{~A}$ & $7.75 \pm 0.63 \mathrm{~A}$ \\
\hline
\end{tabular}

*: Aynı sütunda aynı büyük harflerle gösterilen dozlar arasında Duncan Çoklu Karşılaştırma Testine göre $(P \leq 0.05)$ bir fark yoktur.

Uygulamalardan 28 gün sonra yapılan sayım sonucunda, Ayvalı köyündeki denemede kontrol parsellerinde Menteş köyüne göre daha fazla CUCME elde edilmiştir (Çizelge 4).

\section{Çakal kavunu mücadelesi}

Ayvalı köyündeki denemede CUCME sayıları; kontrol parselinde $14.50 \pm 1.32$ adet $\mathrm{m}^{-2}$, FORA uygulamasında $4.75 \pm 0.47$ adet $\mathrm{m}^{-2}$, NICO uygulamasında $4.00 \pm 0.40$ adet $\mathrm{m}^{-2}$, DITR uygulamasında $3.75 \pm 0.48$ adet $\mathrm{m}^{-2}$, Çapa uygulamasında $3.75 \pm 0.75$ adet $\mathrm{m}^{-2}$, DPTR uygulamasında $3.50 \pm 0.29$ adet $\mathrm{m}^{-2}$, SMTE, ISTC ve MENI uygulamalarında $1.25 \pm 0.25$ adet $\mathrm{m}^{-2}$ bulunmuştur. Menteş köyünde: kontrol parselinde $8.25 \pm 0.85$ adet $\mathrm{m}^{-2}$, FORA ve NICO uygulamalarında $3.75 \pm 0.25$ adet $\mathrm{m}^{-2}$, DPTR uygulamasında $3.75 \pm 0.48$ adet $\mathrm{m}^{-2}$, DITR uygulamasında $2.50 \pm 0.29$ adet $\mathrm{m}^{-2}$, SMTE ve ISTC uygulamalarında $1.50 \pm 0.29$ adet $\mathrm{m}^{-2}$ ve MENI ve ÇAPA uygulamalarında ise $1.00 \pm 0.00$ adet $\mathrm{m}^{-2}$ olarak tespit edilmiştir (Çizelge 4).

Yabancı otlarla mücadelede kullanılan yöntemlerin etkilerini belirlemek için buradan elde edilen sonuçlar yabancı ot mücadelesi yapılmayan kontrol parselleri ile karşılaştırılmıştır (Şekil 2). 


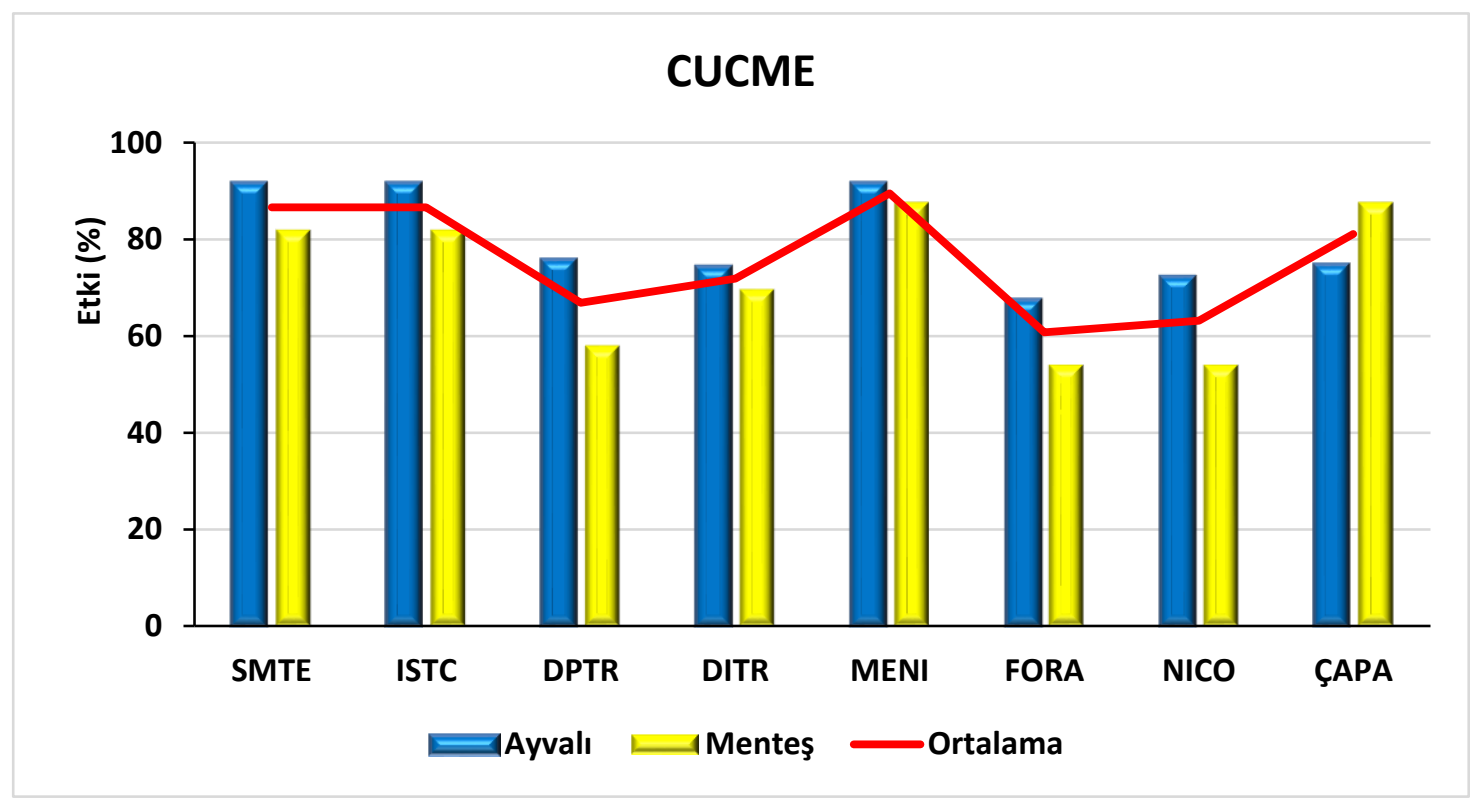

Şekil 2. Çakal kavunu mücadelesinde kullanılan yöntemlerin etkileri.

Figure 2. Effects of control methods used on field muskmelon.

CUCME'ye karşı Ayvalı ve Menteş köylerinde yapılan uygulamalardan elde edilen sonuçlar ve bunların ortalamaları, sırasıyla; ISTC için \% 91.5, \% 81.8 ve $\% 86.6$, SMTE için \% 91.5, \% 91.5 ve $\% 86.7$, DPTR için $\% 75.8, \%$ 58.0 ve 66.9 , DITR için \% 74.3, 69.5 ve 71.9 , MENI için \% $91.5,87.5$ ve 89.5 , FORA için $\% 67.5, \% 54.0$ ve $\% 60.1$, NICO için $\% 72.5, \% 54.0$ ve $\% 63.1$, ÇAPA için $\% 74.8, \%$ 87.5 ve $\% 81.1$ olarak tespit edilmiştir.

\section{Tarla sarmaşığı mücadelesi}

Ayvalı köyündeki denemede CONAR sayıları; kontrol parselinde $5.50 \pm 0.65$ adet $\mathrm{m}^{-2}$, FORA uygulamasında $3.75 \pm 0.48$ adet $\mathrm{m}^{-2}$, NICO uygulamasında $3.0 \pm 0.28$ adet $\mathrm{m}^{-2}$, DITR uygulamasında $3.50 \pm 0.29$ adet $\mathrm{m}^{-2}$, DPTR uygulamasında $2.75 \pm 0.47$ adet $\mathrm{m}^{-2}$, SMTE uygulamasında $2.25 \pm 0.48$ adet $\mathrm{m}^{-2}$, MENI uygulamasında $2.25 \pm 0.25$ adet $\mathrm{m}^{-2}$, ÇAPA uygulamasında $2.00 \pm 0.00$ adet $\mathrm{m}^{-2}$ ve ISTC uygulamasında ise $1.75 \pm 0.25$ adet $\mathrm{m}^{-2}$ bulunmuştur. Menteş köyünde ise kontrol parselinde $7.75 \pm 0.63$ adet $\mathrm{m}^{-2}$, FORA, NICO ve DITR uygulamalarında $5.25 \pm 0.47$ adet $\mathrm{m}^{-2}$, DPTR uygulamasında $4.00 \pm 0.41$ adet $\mathrm{m}^{-2}$, SMTE uygulamasında $3.50 \pm 0.28$ adet $\mathrm{m}^{-2}$, ISTC ve MENI uygulamalarında $2.75 \pm 0.25$ adet $\mathrm{m}^{-2}$ ve ÇAPA uygulamasında ise $2.25 \pm 0.25$ adet $\mathrm{m}^{-2}$ olarak tespit edilmiştir (Çizelge 4).

Yabancı otlarla mücadelede kullanılan yöntemlerin etkilerini (\%) belirlemek için uygulama parsellerinden elde edilen sonuçlar yabancı ot mücadelesi yapılmayan kontrol parselleri ile karşılaştırılmıştır. Buna göre; CONAR'a karşı kullanılan mücadele yöntemlerinin çalışmaların yapıldığı Ayvalı ve Menteş köylerinde uygulanmasından elde edilen sonuçlara ve iki yere ait ortalama sonuçlarına göre sırasıyla; ISTC için \% 60.5, \% 54.8 ve $\% 57.6$, SMTE için $\% 68.3, \% 65.0$ ve $\% 66.6$, DPTR için $\% 50.8, \% 48.5$ ve 49.6 , DITR için $\% 35.3,32.3$ ve 33.8 , MENI için \% 58.5, 65.0 ve 61.8, FORA için \% $31.8, \% 32.3$ ve $\% 32.0$, NICO için \% 35.3 , \% 32.3 ve $\% 33.8$, ÇAPA için $\%$ 62.0, \% 70.8 ve \% 66.4 olarak saptanmıştır (Şekil 3). 


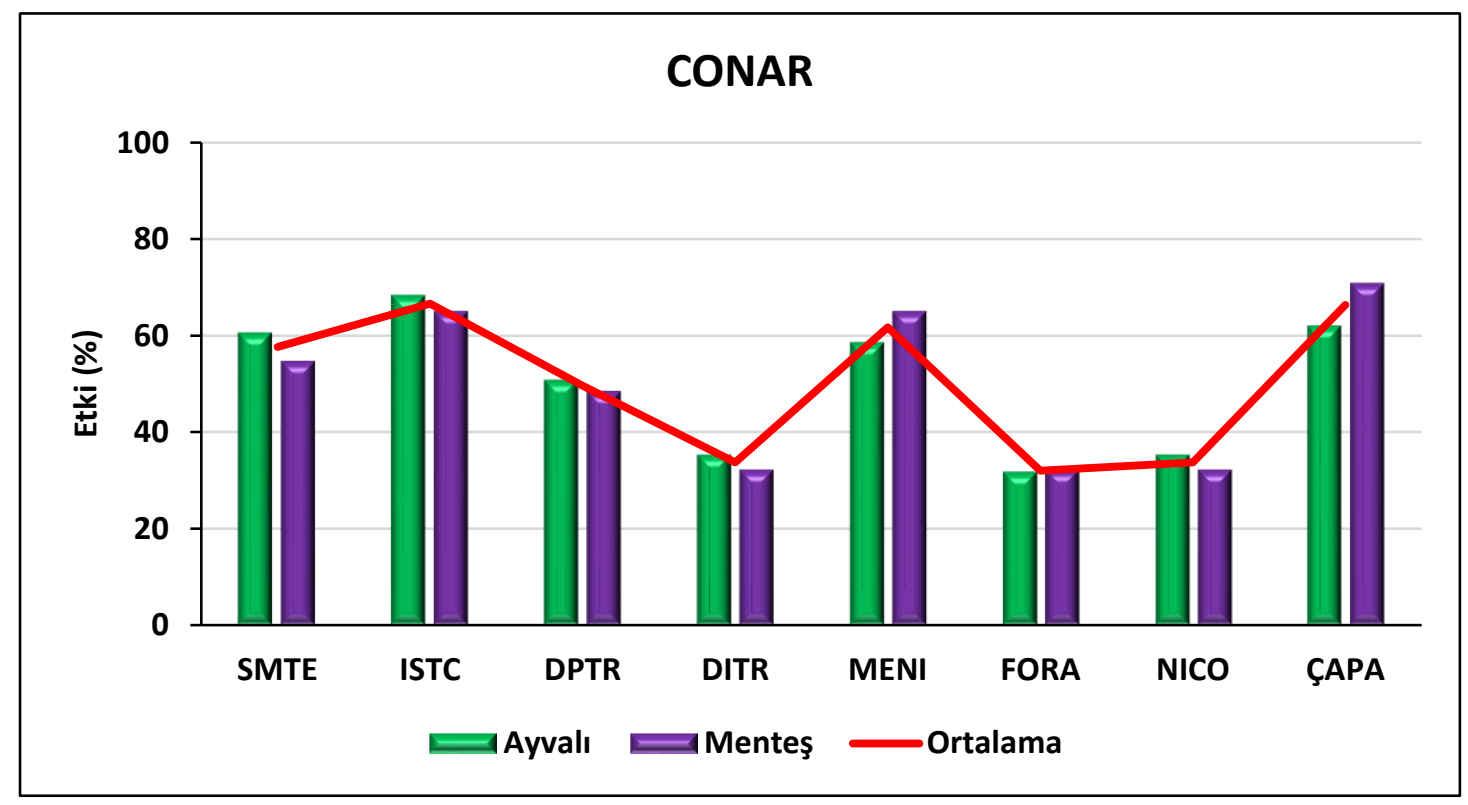

Şekil 3. Tarla sarmaşığı mücadelesinde kullanılan yöntemlerin etkileri.

Figure 3. Effects of control methods used on field bindweed.

Çalışma genel olarak değerlendirildiğinde CUCME'ye karşı uygulanan mücadele yöntemleri Ayvalı köyündeki denemeler daha etkili bulunmuştur. Uygulanan herbisitlerden çıkıs öncesi uygulanan SMTE ve ISTC ile çıkış sonrası uygulanan MENı uygulamaları \% 90.0'ın üzerinde etkili olmuşlardır. Çapa, çıkış öncesi uygulanan DPTR ve çıkış sonrası uygulanan DITR ile NICO \% 70.0 üzerinde etkili olurken FORA \% 67.5 etki ile bunların altında kalmıştır. Menteş köyündeki denemede ise uygulamaların tamamı \% 90.0'ın altında kalmıştır. Burada özellikle çapalama ve MENI uygulaması \% 87.5 ile en iyi sonucu vermiştir. Ayrıca, SMTE ve ISTC uygulamaları \% 81.8 ile bunları takip etmektedir. Diğer uygulamaların tamamı \% 70.0'lerin altında kalmasına rağmen yine de \% 50.0'lerin üzerinde etki göstermişlerdir. Ortalama etkilere bakıldığında uygulamaların tamamı \% 90.0'ın altında kalmasına rağmen MENI, SMTE, ISTC ve ÇAPA \% 80.0'lerin üzerinde diğerleri ise \% 60.0-\% 70.0 arasında etki göstermişlerdir. Çalışmada CUCME'ye karşı kullanılan bazı herbisitlerin ümitvar olduğu anlaşılmaktadır. Ülkemizin şimdilik Çukurova bölgesinde oldukça yüksek oranda yayılma gösteren, ancak daha sonra birçok bölgeye yayılabileceği tahmin edilen çakal kavununa karşı bu herbisitlerin başarılı olabileceği düşünülmektedir. Özer ve ark. (1998), mısır tarımında çapalamanın çok ağır topraklarda önemli olduğunu, çoğu zaman çapalamanın ekonomik olmadığııı, ancak yabancı otlarla mücadelede herbisit kullanımının daha uygun olduğunu belirtmelerine rağmen CUCME'ye karşı MENI, SMTE, ISTC uygulamaları ümitvar görülmekle birlikte bunların çapa ile desteklenmesi halinde başarının daha yüksek olabileceği beklenmektedir. Gözübenli ve ark. (2000), yaptıkları çalışma sonuçlarına göre; mısır üreticilerinin çıkış öncesi herbisit kullanma eğiliminin yüksek olmayıp daha çok çıkış sonrası herbisit kullanma eğiliminde olduğuna dikkat çekmektedirler. Çalışmada çıkış öncesi uygulanan SMTE, ISTC'nin çıkış sonrası kullanılan MENI'ye yakın etki gösterdikleri görülmektedir. Mısır üreticisinin birinci ürün mısırda herbisit kullanımına pek olumlu bakmadıkları bilinmekte olup CUCME'nin biyolojisi itibari ile birinci ürün mısırda problem olması beklenmemekle birlikte ikinci ürün mısırda sorun ortadadır. Üremiş ve ark. (2009) ve Gökgöz (2010) mısır tarlasında bulunan yabancı ot türlerinin dikkate alınarak uygun herbisit seçiminin ve el çapasının özellikle tek yıllık yabancı otların mücadelesindeki önemini belirtmişlerdir. Bu nedenle CUCME'ye karşı mücadele programı hazırlanırken çıkış öncesi herbisitlerin göz ardı edilemeyeceği gerekirse bunların ÇAPA ile desteklenebileceği düşünülmektedir.

CONAR'a karşı uygulanan mücadele yöntemleri genel olarak değerlendirildiğinde herbisitler açısından Ayvalı köyündeki denemeler (MENI hariç) daha etkili bulunmuştur. Burada uygulanan herbisitlerden hiçbiri \% 70.0'lerin üzerinde etki göstermemiştir. Ancak, çıkış öncesi kullanılan ISTC ve SMTE ile ÇAPA uygulaması \% $60.0^{\prime}$ ların üzerinde etkili olmuşlardır. Ayrıca, MENI ve DPTR uygulamaları \% 50.0'lerin üzerinde etkili olurken diğerleri \% 40.0'ların altında kalmıştır. Menteş köyündeki denemedeki herbisit uygulamalarının tamamı \% 70.0'in altında kalmıştır. Ancak, ÇAPA uygulaması $\% 70.8$ etki ile \% 70.0'lerin üzerinde etki göstermiştir. Diğer uygulamalar ise Ayvalı köyündeki deneme ile benzer 
gerçekleşmiştir. ISTC ve MENI \% 60.0'ları, SMTE'nin etkisi $\% 50.0$ 'nin üzerinde olurken diğerleri \% 50.0'lerin altında kalmıştır. Ortalama etkilere bakıldığında uygulamaların tamamı \% 70.0'in altında kalmasına rağmen ISTC, ÇAPA ve MENI \% 60.0'ların üzerinde etki gösterirken SMTE \% 50.0 'nin üzerinde etki göstermiştir. Ancak, diğerleri \% 50.0 'nin altında etki göstermişlerdir. Bruce ve Kells (1997), nicosulfuronun çok yıllık rizomlu yabancı otlar üzerinde yüksek etkili olduğunu bildirmişlerdir. Ancak bu çalışmada NICO'nun etkisi oldukça düşük oranda gerçekleşmiştir, bunun nedeninin ekolojik faktörlerin farklılıklarından kaynaklanabileceği düşünülmektedir. Uysal (2012) Tokat'ta mısırda CONAR'a karşı uygulanan FORA'nın normal ve iki kat dozlarının, sırasıyla \% 45- \% 55 arasında etkiye sahip olduğunu, NICO'nun ise her iki doz için de \% 35 oranında etkide bulunduğunu bildirmekte olup sonuçlar bu çalışmayla da oldukça benzerdir.

Ülkemizde pamuk kültür bitkisinde Convolvulus arvensis'e karşı ruhsatlı herhangi bir herbisit bulunmamaktadır. Üreticilerin bu sorununa çözüm bulunması hem üreticilerimiz açısından hem de ülke ekonomimiz açısından önem arz etmektedir. Ancak, mısırda MENI bazı geniş yapraklı yabancı otlarla birlikte CONAR'a karşı ruhsatlı olmasına rağmen etki \% 58.5-65.0 arasında etkili olabilmiştir. Çatıkkaş (2014) CONAR'a karşı foramsulfuron + iodosulfuron-methyl sodium uygulamasının \% 66 ve \% 62,5 etki gösterdiğine dikkat çekmektedirler. Ancak bu çalışmada etki \% 40'ın altında kalmış olup aradaki farkın çevre kaynaklı olabileceği düşünülmektedir. Mısırda CONAR'ın mücadelesinde kullanılan çıkış öncesi ve çıkış sonrası herbisit uygulamalarının etkisi genel olarak \% 70'lerin üzerine çıkamamıştır. Başka çalışmalarda da çok fazla etkili ve dikkat çekici sonuçlar bulunmamaktadır. Mısır alanlarındaki CONAR'ın yaygınlık ve yoğunluğu dikkate alındığında mutlaka bir çözüm beklenmektedir. Klein ve ark. (1994)'na atfen Uysal (2012), çapalama ve elle ot alımının tek yıllık erken dönemdeki yabancı otlar için en iyi kontrol yöntemleri olduğunu, ancak bunların özellikle çok yıllık yabancı otları kısa süreli olarak kontrol ettiğini, çok yıllık yabancı otlar için sistemik etkili herbisit uygulamasının daha uygun olduğu belirtilmiştir. Bu nedenle daha sonraki çalışmalarda bazı çıkış öncesi ve çıkış sonrası ilaçların bir program çerçevesinde birlikte değerlendirilmesi, ayrıca bu ilaçlama programının çapalama ile desteklenmesi belki çözüm arayışında bir ışık olabilecektir.

Sonuç olarak, ülkemiz tarım alanlarında ilk kez 2015 yılında saptanan ve Çukurova bölgesinin neredeyse tamamına kısa süre içerisinde yayılan çakal kavunu (Cucumis melo L. var. agrestis Naudin, CUCME) ve uzun yıllardır ciddi sorun oluşturan tarla sarmaşığı (Convolvulus arvensis L., CONAR)'nın, mücadelesine yönelik çalışmalar Adana'nın İmamoğlu ilçesine bağlı Ayvalı ve Menteş köylerindeki mısır tarlalarında 2017 yılında yapılmıştır. Çalışmada CUCME'ye karşı kullanılan bazı herbisitlerin ümitvar olduğu (SMTE, ISTC ve MENI) belirlenmiştir. Ülkemizin şimdilik Çukurova bölgesinde oldukça yüksek oranda yayılma gösteren, ancak daha sonra birçok bölgeye yayılabileceği tahmin edilen çakal kavununa karşı bu herbisitlerin başarılı olabileceği düşünülmektedir. CONAR'a karşı herbisitleri etkisi \% 70 'lerin altında kalmıştır, sadece çapalamanın başarısı \% 70 'ler dolayındadır. Singer ve ark. (2000) misır yetiştiriciliğinde yabancı otlara karşı öncelikle ekim nöbeti, diğer kültürel önlemler ve gerekli durumlarda herbisit uygulaması tek başına veya diğer yöntemlerle birlikte kullanılabileceğine dikkat çekilmektedir. Bu bilgiler ışığında daha sonraki çalışmalarda özellikle farklı dönemlerde uygulanan farklı etki mekanizmalarına sahip herbisitlerin birlikte kullanılacağı hatta bunların çapa ile destekleneceği çalışmaların Entegre Mücadele ilkeleri doğrultusunda çalışılmasında ve uygun görülenlerin hızlı bir şekilde uygulamaya aktarılmasında yarar görülmektedir.

\section{ÖZET}

Amaç: Bu çalışma, Çukurova bölgesi mısır alanlarında bulunan çakal kavunu (Cucumis melo var. agrestis Naudin, CUCME) ve tarla sarmaşığı (Convolvulus arvensis L., CONAR)'nın mücadelesinde bazı herbisitlerin ve çapalamanın etkisini belirlemek amacıyla yapılmıştır.

Yöntem ve Bulgular: Çalışma, 2017 yılında (HaziranKasım) Ayvalı ve Menteş/Imamoğlu (Adana)'nda yapılmıştır. Denemeler Tesadüf Blokları Deneme Deseni'ne göre 9 karakterli (çıkış öncesi, Isoxaflutole $\left(225 \mathrm{~g} \mathrm{l}^{-1}\right)$ + Thiencarbazone-Methyl $\left(90 \mathrm{~g} \mathrm{I}^{-1}\right)$ + Cyprosulfamide $\left(150 \mathrm{~g} \mathrm{l}^{-1}\right) \quad\left(\right.$ ISTC, $\left.30 \mathrm{ml} \mathrm{da}^{-1}\right)$; SMetolachlor (312.5 $\left.\mathrm{g} \mathrm{l}^{-1}\right)$ + Terbuthylazine $\left(187.5 \mathrm{~g} \mathrm{l}^{-1}\right)$ (SMTE, $\left.500 \mathrm{ml} \mathrm{da}{ }^{-1}\right)$; Dimethenamid-P $\left(280 \mathrm{~g} \mathrm{l}^{-1}\right)+$ Terbuthylazine $\left(250 \mathrm{~g} \mathrm{l}^{-1}\right)$ (DPTE, $\left.300 \mathrm{ml} \mathrm{da}^{-1}\right)$; çıkış sonrası, Dicamba (\% 50) + Tritosulfuron (\% 25) (DITR, 25 $\mathrm{ml} / \mathrm{da}$; Mesotrione $\left(75 \mathrm{~g} \mathrm{l}^{-1}\right)+$ Nicosulfuron $\left(30 \mathrm{~g} \mathrm{I}^{-1}\right)$ (MENI, $200 \mathrm{ml} \mathrm{da}^{-1}$ ); Foramsulfuron \% 30 + lodosulfuronmethyl-sodium \% 1 + Isoxadifen-ethyl \% 30 (FORA, $15 \mathrm{ml}$ $\mathrm{da}^{-1}$ ) ve Nicosulfuron $\left(40 \mathrm{~g} \mathrm{I}^{-1}\right)$ (NICO, $\left.125 \mathrm{ml} \mathrm{da}^{-1}\right)$, Çapa ve Kontrol) ve 3 tekerrürlü olarak kurulmuştur. CUCME ve CONAR'a karşı kullanılan mücadele yöntemlerinin Ayvalı ve Menteş köylerindeki uygulanmalarından elde edilen sonuçları ve bunların ortalamaları, sırasıyla; CUCME için: ISTC (\% 91.5, 81.8 ve 86.6), SMTE (\% 91.5, 91.5 ve 86.7 ), DPTR (\% 75.8, 58.0 ve 66.9 ), DITR (\% 74.3, 
69.5 ve 71.9), MENI (\% 91.5, 87.5 ve 89.5), FORA (\% 67.5, 54.0 ve 60.1 ), NICO (\% 72.5, 54.0 ve 63.1 ), ÇAPA (\% 74.8, 87.5 ve 81.1 )'dır. CONAR için ise ISTC (\% 60.5, 54.8 ve 57.6), SMTE (\% 68.3, 65.0 ve 66.6), DPTR (\% 50.8, 48.5 ve 49.6), DITR (\% 35.3, 32.3 ve 33.8), MENI (\% 58.5, 65.0 ve 61.8), FORA (\% 31.8, 32.3 ve 32.0), NICO (\% 35.3, 32.3 ve 33.8), ÇAPA (\% 62.0, 70.8 ve 66.4)'dır.

Genel Yorum: Çalışmada CUCME'ye karşı kullanılan bazı herbisitlerin ümitvar olduğu (SMTE, ISTC ve MENI) anlaşılmaktadır. Ülkemizin şimdilik Çukurova bölgesinde oldukça yüksek oranda yayılma gösteren, ancak daha sonra birçok bölgeye yayılabileceği tahmin edilen çakal kavununa karşı bu herbisitlerin başarılı olabileceği beklenmektedir. CONAR'a karşı herbisitlerin etkisi \% 70 lerin altında kalmış, sadece çapalamanın başarısı ise $\% 70$ 'ler dolayındadır.

Çalışmanın Önemi ve Etkisi: Daha sonraki çalışmalarda özellikle farklı dönemlerde uygulanan farklı etki mekanizmalarına sahip herbisitlerin birlikte kullanılacağı hatta bunların çapa ile destekleneceği çalışmaların Entegre Mücadele ilkeleri doğrultusunda çalışılmasında ve uygun görülenlerin hızlı bir şekilde uygulamaya aktarılmasında yarar bulunmaktadır.

Anahtar Kelimeler: Cucumis melo var. agrestis, Convolvulus arvensis, herbisitler, çapalama, entegre mücadele.

\section{ÇIKAR ÇATIŞMA BEYANI}

Yazarlar çalışma konusunda çıkar çatışmasının olmadığını beyan eder.

\section{ARAŞTIRMACILARIN KATKI ORANI BEYANI}

Yazarlar çalışmaya eşit oranda katkı sağlamış olduklarını beyan eder.

\section{KAYNAKLAR}

Americanos PG (1994) Convolvulus arvensis L. weed management for developing countries (In: Labrada R, Caseley JC, Parker, C, Eds.). FAO Plant Production and Protection Paper 120. Rome, Italy: FAO, 95-99.

Anonim (2017) Tarım ve Orman Bakanlığı Meteoroloji Genel Müdürlüğü Verileri.

Bruce AB, Kells JJ (1997) Quackgrass (Elytrigia repens) control in corn (Zea mays) with nicosulfuron and primisulfuron. Weed Tech. 11: 373-378.

CABI (2018) Crop protection compendium online data sheet. Convolvulus arvensis (bindweed). CABI Publishing 2018. www.cabi.org/ISC. Son erişim: 10 Ağustos 2018.

Çatıkkaş U (2014) Mısır (Zea mays L.) yetiştiriciliğinde sorun olan yabancı otlara karşı alternatif uygulamaların etkinliklerinin araştırılması. Yüksek Lisans Tezi, Ege Üni. Fen Bil. Enst. 63s. İzmir.

Doğan MN, Benlioğlu K (2007) Herbisitlere tolerant transgenik kültür bitkileri. Tarım İlaçları Kongre ve Sergisi (25-26 Ekim 2007, Ankara) Bildirileri, 116-131.

Doğan MN, Ünay A, Boz Ö, Albay F (2004) Determination of optimum weed control timing in maize (Zea mays L.). Turk. J. Agric. For. 28: 349-354.

Doğan MN, Boz Ö, Ünay A (2005) Efficacies of reduced herbicide rates for weed control in maize (Zea mays L.) during critical period. J. Agronomy 4: 44-48.

Fuksa P, Slivkova P, Stepanek P (2002) Agricultural extension in the Czech Republic and EU countries with the emphasis on forage crops. Proceedings. Ceska Zemedelska Univ. 130: 77-79.

Gökgöz Ş (2010) Samsun koşullarında atdişi mısırda (Zea mays indentata Sturt.) yabancl ot kontrol yöntemlerinin verime ve verim unsurlarına etkisi. Yüksek Lisans Tezi, Namık Kemal Üni. Fen Bil. Enst. 88s. Tekirdağ.

Gözübenli H, Şener O, Konuşkan Ö ve Kılınç M (2000) Hatay'da mısır tarımının genel durumu, sorunları ve çözüm önerileri. MKÜ Ziraat Fak. Derg. 5: 30-41.

Güncan A (2019) Yabancı otlar ve mücadele prensipleri. (Güncelleştirilmiş ve ilaveli yedinci baskı) Selçuk Üniversitesi Basımevi, Konya, 269s.

Han E (2016) Bazı mısır çeşitlerinin dane verimleri ile silaj ve kalite özelliklerinin belirlenmesi. Yüksek Lisans Tezi, Ordu Üni. Fen Bil. Enst. 65s. Ordu.

Hançerli L (2017) Çukurova bölgesi mısır ekim alanlarında önemli yabancı ot türlerinin belirlenmesi ve bunların mücadelesinde kullanılabilecek örtücü bitki türlerinin araştırılması. Yüksek Lisans Tezi, Çukurova Üni. Fen Bil. Enst. 102s. Adana.

Işık D, Mennan H, Bükün B, Oz A ve Ngouajio M (2006). Türkiye'de mısır ot kontrolü için kritik dönem. Yabancı Ot Tek. 20: 867-872.

Kadıoğlu i, Üremiș i, Uluğ E, Boz Ö, Uygur FN (1998) Researches on the economic thresholds of wild oat (Avena sterilis L.) in wheat fields in Çukurova region of Turkey. Türkiye Herboloji Derg. 1: 18-24.

Kaya H, Üremiş i (2020) Hatay soğan alanlarında yabancı otlarla mücadele yöntemleri üzerine araştırmalar. MKÜ Tar. Bil. Derg. 25: 27-35.

Knezevic SZ, Weise SF, and Swanton CJ (1994) Interference of redroot pigweed (Amaranthus retroflexus L.) in corn (Zea mays L.). Weed Sci. 42: 568-573.

Knezevic SZ, Horak MJ, Vanderlip RL (1997) Relative time of redroot pigweed (Amaranthus retroflexus) emergence is critical in pigweed-sorghum (Sorghum 
bicolor) competition. Weed Sci. 45: 502-508.

Kudsk P, Streibig JC (2003) Herbicides - a two edged sword. Weed Res. 43: 90-102.

Kuntay S (1944) Türkiye hububat mahsulu içinde tohumları bulunan yabanciotlar üzerinde araştırmalar. T.C. Ziraat Vekaleti, Neşriyat Müdürlüğü, No: 582, 126s. Ankara.

Lacey AJ (1985) Weed control in pesticide application: Principles and practice, (Haskell, P.T., ed.), Oxford Science Publications, Oxford, U.K. pp: 456-485.

Mengüç Ç (2018) Herbisit toksisitesi ve yabancı otlara karşı alternatif mücadele stratejileri. Türkiye Herboloji Derg. 21: 61-73.

Oerke EC, Dehne HW (2004) Safeguarding protection losses in major crops and the role of crop protection. Crop Protect. 23: 275-285.

Özer Z, Kadıoğlu I, Önen H, Tursun N (1998) Herboloji (Yabancı Ot Bilimi, 2. baskı), Gaziosmanpaşa Üni. Ziraat Fak. Yay. No: 20, Kitaplar Serisi No: 10, 403s. Tokat.

Rajcan I, Swanton CJ (2001) Understanding maize-weed competition: resource competition, light quality and the whole plant. Field Crops Res. 71: 139-150.

Singer JW, Cox WJ, Hahn RR, Shields EJ (2000) Cropping system effects on weed emergence and densities in corn. Agronomy J. 92: 754-760.

Süzer S (2003) Mısır tarımı. Trakya Tarımsal Araştırma Enst. Edirne.

Tepe I (2014) Yabancı otlarla mücadele. Sidas Medya Ltd. Şti. 292s. Van.

Thonke KE (1991) Political and practical approach in Scandinavia towards reducing herbicide inputs. Brighton Crop Protection Conference, Brighton, UK, Proceedings, 1183-1190.

TUiK (2018) Bitkisel üretim ve istatistik veri tabanı, http://tuikapp.tuik.gov.tr/ bitkiselapp/bitkisel.zul, (Son erişim: Nisan 2018).

Uludağ A, Uremis I, Ulger AC, Cakir B, Aksoy E (2006) The use of maize as replacement crop in trifluralin treated cotton fields in Turkey. Crop Protect. 25: 275-280.

Uludağ A, Uremis I, Tursun N, Bukun B (2012) A review on critical period for weed control in Turkey. The $6^{\text {th }}$ International Weed Science Congress (17-22 June 2012, Hangzhou, China) Abstracts: 37.
Uludağ A, Uremis I, Arslan M (2018) Biological weed control, Chapter:7. Non-Chemical Weed Control, (Eds.: Jabran K, Chauhan BS) 115-132.

Uludag, A, Uremis I, Kaya Y (2021) Ayçiçeğinde yabancı otlar ve önemi. Ayçiçeği tarımı (Ed. Kaya Y). Tarım Gündem, Nobel Akademik Yayıncılık, İzmir, 101-125.

Uremis I, Uludag A, Ulger AC, Cakır B (2009) Determination of critical period for weed control in the second crop corn under Mediterranean conditions. African J. Biotech. 8: 4475-4480.

Uysal B (2012) Mısırda sorun olan yabancı otlara karşı kullanılan bazı herbisitlerin farklı dozlarının yabancı otlanmaya ve mısır verimine etkisinin araştırılması. Yüksek Lisans Tezi, Gaziosmanpaşa Üni. Fen Bil. Enst., 59s. Tokat.

Uygur FN, Koch W, Walter H (1986) Çukurova bölgesi buğday-pamuk ekim sistemindeki önemli yabancı otların tanımı. PLITS, 4 (1). Josef Margraf, Aichtal, Germany, 169s.

Üremiş I, Karaat Ş, Gönen O, Canıhoş E, Kütük H, Ekmekçi U, Çetin V, Aytaş M, Kadıŏlu i (1996) Çukurova Bölgesi'nde zirai mücadele ilaç kullanımının genel değerlendirilmesi. II. Ulusal Zirai Mücadele ilaçları Simpozyumu (18-20 Kasım 1996, Ankara) Bildiriler: 73-79.

Üremiş i, Uludağ A (2020) Patateste yabancı otlar ve mücadelesi. Patates (Ed. Çalışkan ME). Tarım Türk Derg. Yay. İzmir, 98-111.

Üremiş i, Soylu S, Kurt Ş, Soylu EM, Sertkaya E (2020) Hatay ili havuç ekim alanlarında bulunan yabancı ot türleri, yaygınlıkları, yoğunlukları ve durumlarının değerlendirilmesi. Tekirdağ Ziraat Fakültesi Derg. 17: 211-228.

Xu H, Su W, Zhang D, Sun L., Wang H, Xue F, Zhai S, Zou $Z$, Wu R (2017) Influence of environmental factors on Cucumis melo L. var. agrestis Naud. seed germination and seedling emergence. Plos One 12(6): e0178638.https://doi.org/10.1371/journal.pone.017 8638.

Zimdahl RL (2018) Fundamentals of weed science. 5th Edition, Academic Press, 758p. 